\title{
CONSEQUÊNCIAS DO EFEITO DE BORDA NA COLONIZAÇÃO DO EPIFILO EM UM FRAGMENTO FLORESTAL
}

\author{
Michele Matos dos Santos ${ }^{1}$ \\ Jessika da Silva Nunes ${ }^{2}$ \\ Carine Emer ${ }^{3}$
}

Resumo: Em florestas tropicais, o efeito de borda gerado pela fragmentação do habitat causa mudanças na estrutura das comunidades e nos processo ecológicos. Neste trabalho testamos como o efeito de borda influencia a taxa de cobertura do epifilo em um fragmento de floresta tropical. Realizamos o estudo na ARIE Santa Genebra, no interior e na borda da mata. Estabelecemos 10 transectos de $50 \mathrm{~m}$ em cada habitat e a cada $5 \mathrm{~m}$, coletamos as folhas que tocassem um bastão de $1 \mathrm{~m}$ altura. Coletamos um total de 659 folhas, classificadas em 103 morfoespécies. A taxa de cobertura epifilica foi significativamente maior no interior da mata ( $p$ <001). Nossos resultados demonstram como o efeito de borda pode influenciar na cobertura do epifilo, o que pode acarretar efeitos negativos para a vegetação. Além disso, o epifilo é rico em microrganismos associados, que podem, consequentemente, desaparecer do sistema por efeitos em cascata gerados pela perda da cobertura epifilica.

Palavras-chave: Dietas Fragmentação; Mata Atlântica; Taxa de cobertura do epifilo; Dano foliar.

\footnotetext{
${ }^{1}$ Ecologia/Universidade Estadual Paulista, Rio Claro, Brasil. E-mail: matos.michele@hotmail.com.

${ }^{2}$ Ecologia/Universidade Estadual Paulista, Rio Claro, Brasil. E-mail: jessika_silvanunes@hotmail.com.

${ }^{3}$ Pós doutoranda no departamento de Ecologia/Universidade Estadual Paulista, Rio Claro, Brasil. E-mail: c.emer09@gmail.com.
} 